\title{
The Attachment of Garbohydrate in Ovomucoid
}

\author{
By FREDA K. HARTLEY AND F. R. JEVONS \\ Department of Chemistry, University of Manchester
}

(Received 6 December 1961)

\begin{abstract}
Very little information has been available until recently about the nature of the bonds between the protein and carbohydrate moieties in complexes containing them in covalent linkage (BettelheimJevons, 1958). It appears that aspartic acid is directly linked to the carbohydrate in hen-egg albumin (Cunningham, Nuenke \& Nuenke, 1957; Jevons, 1958; Johansen, Marshall \& Neuberger, 1958,1961 ) and in human $\gamma$-globulin (Rosevear \& Smith, 1958, 1961). Gottschalk \& Murphy (1961) have provided evidence that, in the sialic acidrich submaxillary mucoprotein, $N$-acetylgalactosamine residues form glycosidic ester bonds with the
\end{abstract} $\beta$ - and $\gamma$-carboxyl groups of aspartic acid and glutamic acid respectively. With chondroitin sulphate (where the carbohydrate is of a different type, containing uronic acid and sulphate but not neutral sugar), the complex with protein extractable from pig trachea, after digestion with papain, retains no amino acid except serine in stoicheiometrically significant amounts, and bonds between this and acidic groups in the carbohydrate were postulated (Muir, 1958).

This paper reports attempts to obtain information about the protein-carbohydrate link in hen ovomucoid. This mucoprotein was identified with the antitryptic factor of egg white by Lineweaver \& Murray (1947). Its carbohydrate component was investigated by Stacey \& Woolley $(1940,1942)$, who showed that, besides glucosamine and mannose, some galactose is present, and gave the molar ratios of these sugars as $7: 3: 1$. However, Gottschalk \& Ada (1956) found 14.1, 4.3 and 1.4\% of the three sugars respectively, and Bragg \& Hough (1961) reported values of $12.6,6.3$ and $1.7 \%$. It remains doubtful whether sialic acid is present in stoicheiometrically significant amounts (Jevons, 1960). The protein moiety contains the usual complement of amino acids (Lewis, Snell, Hirshman \& Fraenkel-Conrat, 1950); a single $N$. terminal residue of alanine (Fraenkel-Conrat \& Porter, 1952) and a single $C$-terminal residue of phenylalanine (Pénasse, Jutisz, Fromageot \& Fraenkel-Conrat, 1952; Turner \& Schmerzler, 1954) have been found. A careful investigation of the amide nitrogen gave a value of 9 residues/ molecule (Marshall \& Neuberger, 1960). The molecular weight appears to be about 28000 (Line- weaver \& Murray, 1947; Fredericq \& Deutsch, 1949; Lewis et al. 1950).

In the present work, ovomucoid was treated with proteolytic enzymes to split off a large proportion of the protein moiety; the resulting carbohydrate-rich fragment, referred to as the 'protease fragment', was isolated from the digest and characterized in several ways. In addition, the reducing power of and some effects of heating in dilute alkali on both the protease fragment and intact ovomucoid were examined. A preliminary account of the findings has been published (Hartley \& Jevons, 1962).

\section{EXPERIMENTAL}

Chromatographic and electrophoretic systems. Paper chromatography and electrophoresis were carried out on Whatman no. 1 and no. $3 \mathrm{MM}$ paper, the latter (used for preparative purposes) having been previously washed chromatographically with $5 \%(v / v)$ acetic acid. Descending development was used for chromatography, which was done at $26^{\circ}$. The solvent systems are designated thus: A, phenol-water $(4: 1, \mathrm{v} / \mathrm{v})$; B, butan-1-ol-acetic acidwater $(4: 1: 5$, by vol.); C, butan-1-ol-pyridine-water (6:4:3, by vol.) (Wilson, 1959); D, 2-methylbutan-2-ol saturated with $0.05 \mathrm{M}$-potassium phthalate, $\mathrm{pH} 6 \cdot 0$, used on paper impregnated with the same buffer (Blackburn \& Lowther, 1951).

Electrophoresis was carried out with paper and buffer vessels completely immersed in white spirit (Shell-Mex and British Petroleum Ltd.); 2000v was applied across $50 \mathrm{~cm}$. paper for $1 \mathrm{hr}$. unless otherwise indicated. The buffer systems are designated thus: E, formic acid-water $(3: 37, \mathrm{v} / \mathrm{v} ; \mathrm{pH} 2) ; \mathrm{F}$, pyridine-acetic acid-water $(1: 9: 190$, by vol.; pH 3.5).

Papers were dried at temperatures not exceeding $60^{\circ}$. To reveal ninhydrin-reactive spots, the reagent was used as a $0.25 \%(w / v)$ solution in acetone, into which the papers were dipped, and reducing sugars were located with the aniline hydrogen phthalate reagent of Wilson (1959).

Determination of hexose. Bound hexose was measured by an orcinol- $\mathrm{H}_{2} \mathrm{SO}_{4}$ reaction based on that of Tillmans \& Philippi (1929). The stock orcinol solution contained $1 \mathrm{~g}$. of orcinol in a mixture of $12.5 \mathrm{ml}$. of concentrated $\mathrm{H}_{2} \mathrm{SO}_{4}$ and $37.5 \mathrm{ml}$. of water. Before use, 1 vol. of this was mixed with 24 vol. of a mixture of $375 \mathrm{ml}$. of concentrated $\mathrm{H}_{2} \mathrm{SO}_{4}$ and $125 \mathrm{ml}$. of water. A $3 \mathrm{ml}$. portion of this reagent was added to $1 \mathrm{ml}$. of the solution to be tested; these were thoroughly mixed and heated at $100^{\circ}$ for $10 \mathrm{~min}$., and the extinction at $500 \mathrm{~m} \mu$ of the cooled solution was measured 
with a Unicam SP. 500 spectrophotometer. The calibration curve was linear over the range $10-100 \mu \mathrm{g}$. of mannose or galactose, the colour yield from the two sugars being the same within the experimental error.

Purification of ovomucoid. Hen's eggs were used on the day of collection. The initial steps of the isolation procedure were precipitation of other egg-white proteins by sodium trichloroacetate $(5 \%, \mathrm{w} / \mathrm{v})$ at $\mathrm{pH} 3.5$, followed by precipitation of the crude ovomucoid by 2 vol. of $95 \%$ $(\mathrm{v} / \mathrm{v})$ ethanol at $0^{\circ}$ and $\mathrm{pH} 6 \cdot 0$, essentially as described by Fredericq \& Deutsch (1949). After thorough dialysis against 4 mM-sodium phosphate buffer, $\mathrm{pH} 6 \cdot 8$, the product was purified on a column of triethylaminoethylammonium cellulose (Serva Entwicklungslabor, Heidelberg, Germany) by the batch method of Jevons (1960), except that the operation was carried out at room temperature. The column was washed with twice its volume of solutions containing buffer as above together with increasing concentrations of $\mathrm{NaCl}$, and the eluates were tested for their ability to inhibit crystalline trypsin (Sigma Chemical Co.), the residual trypsin activity being measured by the method of Schwert \& Takenaka (1955). The inhibitory potencies thus found, referred to absorption at $280 \mathrm{~m} \mu$, were constant for eluates obtained with $\mathbf{0 . 0 1} \mathrm{M}$ and higher concentrations of $\mathrm{NaCl}$. Elution of ovomucoid was completed by raising the $\mathrm{NaCl}$ concentration to $0.2 \mathrm{M}$; traces of a yellow substance, probably a flavoprotein, remained on the column. The purified ovomucoid was dialysed free of salts and stored at $-15^{\circ}$. Concentrations were determined by measuring absorption at $280 \mathrm{~m} \mu\left(E_{\mathrm{cm}}^{1 \%} 4 \cdot 2\right.$, based on the weight obtained after drying a salt-free solution at $98^{\circ}$ ).

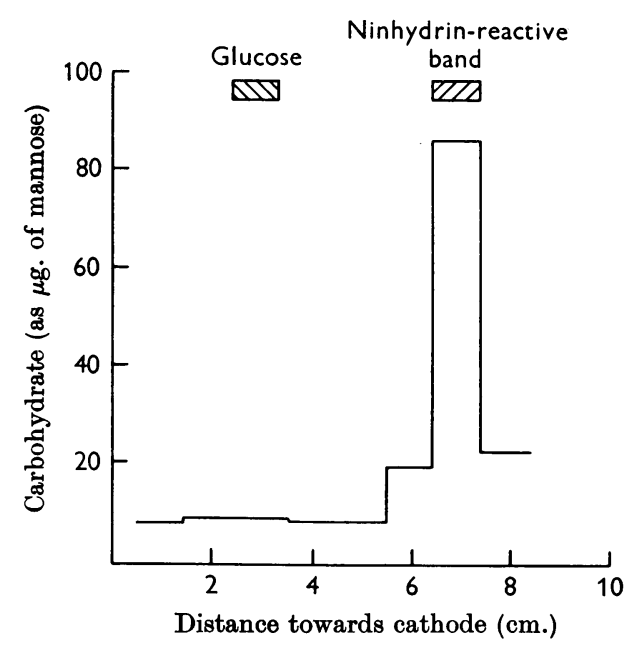

Fig. 1. Purification of the protease fragment by paper electrophoresis. Resin-treated digest, suitably concentrated, was applied as a thin line to washed Whatman no. 3MM paper and subjected to electrophoresis (system E). After drying, a strip was cut off and stained with ninhydrin. From the rest of the paper, strips $1 \mathrm{~cm}$. wide were cut in a direction transverse to that of the potential gradient; these were eluted chromatographically with water, and the eluates were examined for carbohydrate by the orcinol reaction. The values obtained within $5 \mathrm{~cm}$. of the origin represent the paper blank.
Enzymic digestion. To a $1 \%(\mathrm{w} / \mathrm{v})$ solution of ovomucoid, adjusted to $\mathrm{pH} 2$ with $\mathrm{N}-\mathrm{HCl}$, was added 0.1 vol. of a solution of crystalline pepsin (Sigma Chemical Co., St Louis, Mo., U.S.A.) (pepsin : ovomucoid, 1:50 by weight) in $0.01 \mathrm{~N}-\mathrm{HCl}$. The ensuing digestion, which was at $37^{\circ}$ under toluene vapour, resulted in complete loss of antitryptic activity. To follow the course of the degradation, $50 \mu \mathrm{l}$. samples of the incubation mixture were taken at intervals and changes in the pattern of ninhydrin-reactive spots produced in system $\mathbf{E}$ were noted. After 5 days, the digest was adjusted to $\mathrm{pH} 7 \cdot 8$ with aq. $\mathrm{NaHCO}_{3}$, and to it were added the crude trypsin preparation marketed as 'trypsin 1:300' (Nutritional Biochemicals Corp., Cleveland, Ohio, U.S.A.) and crystalline chymotrypsin (Boehringer und Soehne G.m.b.H., Mannheim, Germany) (crude trypsin:chymotrypsin: ovomucoid, 2:1:100, by weight). Incubation was continued at $37^{\circ}$ for a further 2 days. Prolongation of the digestion beyond this time did not alter the amino acid composition of the protease fragment eventually isolated.

Preparation of 'resin-treated digest'. Digests obtained as above were passed through columns of the cation-exchange resin Amberlite IR-120 ( $\mathrm{H}^{+}$form) to remove most of the amino acids and small peptides. After the columns had been washed with water, more than $80 \%$ of the bound hexose was recovered in the eluate, and $95 \%$ of the material absorbing at $280 \mathrm{~m} \mu$ was adsorbed on the resin. The eluate was neutralized with Amberlite IRA-400 ( $\mathrm{HCO}_{3}^{-}$form) and passed through a column of the same resin. Up to $82 \%$ recovery of hexose could be obtained by washing the column with water, but on long columns an appreciable proportion of the hexose-containing material was adsorbed. After elution with $1.0 \mathrm{M}-\mathrm{NaHCO}_{3}$, however, this material had a content of hexose and amino acids similar to that of the unadsorbed material, so that there is no reason to believe that fractionation into different components had been achieved.

The eluate from these two resins, which represents a partially purified preparation of protease fragment, is referred to below as the 'resin-treated digest'.

Purification of protease fragment by paper electrophoresis. When resin-treated digest was submitted to paper electrophoresis at $\mathrm{pH} 2$ (system $\mathrm{E}$ ), the hexose-containing material was found to coincide with the main ninhydrin-positive band (Fig. 1). The material eluted with water from this band is the 'protease fragment' referred to below.

\section{RESULTS}

\section{Characterization of protease fragment}

Component sugars. After hydrolysis in sealed tubes with $2 \mathrm{~N}$-hydrochloric acid at $100^{\circ}$ for $12 \mathrm{hr}$., paper chromatography (system C) followed by staining with aniline hydrogen phthalate gave three spots, corresponding to mannose, galactose and glucosamine. The molar ratio of the first two sugars was estimated by elution (Wilson, 1959) to approximate to $7: 2$, which is close to that obtained by other authors for whole ovomucoid (Stacey \& Woolley, 1942; Gottschalk \& Ada, 1956; Bragg \& Hough, 1961). Glucosamine was not estimated by this method because it gives relatively little colour. 
Component amino acids and glucosamine. Hydrolysis was effected by heating in sealed tubes with $5 \cdot 7 \mathrm{~N}$-hydrochloric acid at $100^{\circ}$ for $12 \mathrm{hr}$. Such hydrolysates yielded, in system $\mathbf{E}$, five ninhydrinreactive spots which were not observed either in the unhydrolysed material or in hydrolysates of eluates from blank areas of filter paper. A sixth spot, running faster than the others and much fainter, was similar in intensity in the hydrolysed paper blank and was therefore ignored. The five main spots were identified by running together with suitable markers in system $\mathbf{E}$, and by eluting them separately and chromatographing the five eluates in system A. Spot 1 (the slowest) was thus found to contain aspartic acid, spot 2 leucine and threonine, spot 3 glucosamine and serine, spot 4 alanine and spot 5 glycine. These identifications were further confirmed with system $B$, and by the diminution in intensity of spot 2 and the complete disappearance of spot 3 when a sample of dried hydrolysate was treated with $60 \mu \mathrm{l}$. of $0.05 \mathrm{~N}$ sodium periodate before electrophoresis. None of the systems used distinguish between leucine and isoleucine, so that leucine is here written for either or both.

Rough quantitative estimation of the above constituents was carried out by running various known concentrations of markers by the side of the hydrolysates and visually comparing the intensities of the ninhydrin spots. Three different systems were used for separation: $F$ for aspartic acid and glucosamine, $\mathrm{B}$ for leucine and $\mathrm{A}$ for all the other amino acids. The results obtained, together with the amount of hexose separately measured by the orcinol method, indicate the following approximate composition of the protease fragment: hexose:glucosamine: aspartic acid: threonine:serine:alanine:glycine:leucine in the proportions $5: 8: 1: 1: 1: 1: 1: 0 \cdot 5$.

In the resin-treated digest, at least three amino acids in addition to the above were found after hydrolysis, one of them being cysteic acid, clearly distinguished from the others by moving towards the positive electrode at $\mathrm{pH} 2$ (system E). Solutions of cystine and cysteine, alone or in combination, and with or without the addition of mannose, galactose, glucosamine and the sulphur-free protein casein, produced no cysteic acid when taken through the same hydrolytic procedure, but fibrinogen, chymotrypsinogen and insulin under similar conditions all gave cysteic acid, though the amounts in each case were only about $4 \%$ of those found when the proteins were oxidized with performic acid (Toennies \& Homiller, 1942) before hydrolysis. It appears probable, therefore, that oxidation of cystine is promoted during peptide-bond cleavage.

Attempted further purification. The protease fragment remained at the origin in system $B$, but it had $R_{F} 0.25$ in system A. After elution in both cases, its content of hexose, glucosamine and amino acids was not detectably altered.

N-Terminal residues. Protease fragment was allowed to react with 1-fluoro-2,4-dinitrobenzene in the presence of trimethylamine as described by Sanger \& Thompson (1953). After hydrolysis in $5 \cdot 7 \mathrm{~N}$-hydrochloric acid at $100^{\circ}$ for $12 \mathrm{hr}$., the ether-extractable DNP-amino acids were separated in system $D$, eluted from the paper with $1 \%$ $(w / v)$ sodium hydrogen carbonate and estimated spectrophotometrically at $350 \mathrm{~m} \mu$. The DNP derivatives of leucine, alanine, aspartic acid and glycine were found, the molar yields $/ 5$ moles of hexose being roughly $0.3,0.2,0.1$ and 0.1 respectively. No DNP-serine or DNP-threonine could be detected. Since no estimate was made of the rates of destruction of the DNP-amino acids, which may be influenced by the presence of carbohydrate (Fraenkel-Conrat \& Porter, 1952), it is not possible to place great reliance on the quantitative aspect of these findings.

Action of carboxypeptidase. Crystalline carboxypeptidase (Sigma Chemical Co.) was incubated for $6 \mathrm{hr}$. with protease fragment, as described by Nicol (1960) for insulin. Examination in system $\mathbf{E}$ failed to reveal that any amino acid had been liberated. Under the same conditions the enzyme preparation released alanine from insulin.

Action of an extract of Aspergillus oryzae. The extract used was 'HYDG enzyme concentrate' (Boehringer und Soehne G.m.b.H.) stated to contain proteases, amylases and esterases. A solution of protease fragment was incubated with the enzyme (enzyme:substrate, $1: 100$ ) at $\mathrm{pH} 7$ for $1 \mathrm{hr}$. at $37^{\circ}$. The product, examined in system $\mathrm{E}$, gave only two ninhydrin-reactive bands, of which one moved at the same rate as the original protease fragment, and the other faster band appeared to be identical with one obtained also from enzyme alone, similarly incubated. It thus appeared that the enzyme had had no effect on the protease fragment. To check this point further, the proteasefragment band from the enzyme incubation mixture was eluted, hydrolysed in acid and shown in system $\mathbf{E}$ to have the same amino acid composition as the starting material.

Isoelectric point. To estimate the isoelectric point, the protease fragment was submitted to paper electrophoresis in a series of buffers covering the $\mathrm{pH}$ range $2-7 \cdot 2$ under otherwise standard conditions. To compensate for movement due to factors other than the charge carried by the protease fragment, such as siphoning and electroosmosis, glucose was also run on each paper. The plot of distance moved (relative to glucose) against pH (Fig. 2) shows that the isoelectric point is in the $\mathrm{pH}$ region 5-6. 


\section{Effect of hot dilute alkali}

Liberation of acid groups. Gottschalk \& Murphy (1961), as part of their evidence for the existence of glycosidic ester bonds in submaxillary mucoprotein, showed that treatment with dilute alkali $(\mathrm{pH} 10 \cdot 4)$ at $80^{\circ}$ released acid groups. This type of experiment was therefore done with ovomucoid, and an apparent acid production was observed, the amount corresponding to about 3 equiv./mole of ovomucoid (Table 1). The interpretation of these results, however, is far from simple.

A correction is needed for the deacetylation of $\mathrm{N}$-acetylglucosamine residues in the mucoprotein. Gottschalk \& Murphy (1961) estimated the recovery of free $\mathrm{N}$-acetylhexosamine by the method of Aminoff, Morgan \& Watkins (1952), but the latter authors showed that the colour yield in their

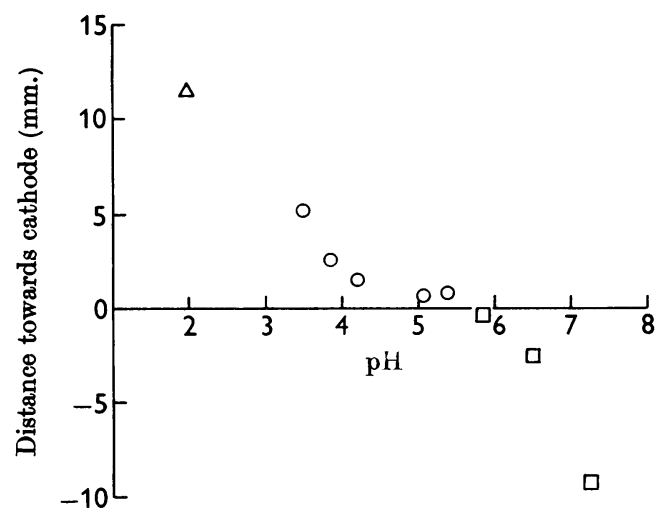

Fig. 2. Movement of the protease fragment, relative to glucose, during paper electrophoresis at different $\mathrm{pH}$ values. A potential gradient of $40 \mathrm{v} / \mathrm{cm}$. was applied for 30 min. in each case. $\triangle$, Formic acid $\left(7 \frac{1}{2} \%, v / v\right), p H ~ 2$; $\bigcirc$, sodium acetate buffer $(0 \cdot 2 \mathrm{M}) ; \square$, sodium phosphate buffer $(0 \cdot 2 \mathrm{M})$. The protease fragment was located with ninhydrin, glucose with aniline hydrogen phthalate.

\section{Table 1. Acid production in hot dilute alkali}

The procedure was based on that of Gottschalk \& Murphy (1961). The initial $\mathrm{pH}$ was adjusted to $10 \cdot 4$ with sodium hydroxide, with a glass electrode, and samples were heated in stoppered flasks in a water bath at $80^{\circ}$ for $6 \mathrm{hr}$. The final $\mathrm{pH}$ was then measured, and similar unheated samples were titrated to that $\mathrm{pH}$ with $5 \mathrm{mN}$-hydrochloric acid from a microburette under nitrogen.

$\begin{array}{lcc}\text { Material } & \begin{array}{c}\text { Final } \\ \mathrm{pH}\end{array} & \begin{array}{c}5 \mathrm{mN}-\mathrm{HCl} \\ (\mathrm{ml} .)\end{array} \\ \text { Water only } & 10 \cdot 01 & 0 \cdot 9 \\ \text { Ovomucoid (160 mg.) } & 8 \cdot 61 & 4 \cdot 6 \\ \text { Ovomucoid (160 mg.) } & 8 \cdot 61 & 4 \cdot 8 \\ \text { Casein (120 mg.) } & 9 \cdot 96 & 3 \cdot 2 \\ \text { Chymotrypsinogen (120 mg.) } & 9 \cdot 30 & 4 \cdot 9 \\ \text { Resin-treated digest } & 9 \cdot 95 & 2 \cdot 2\end{array}$

(from $50 \mathrm{mg}$. of ovomucoid) reaction depends on the extent of pretreatment with alkali. As a more direct measure of deacetylation, therefore, the amount of acetic acid resulting from the alkaline treatment of ovomucoid was measured by bringing the solution to $\mathrm{pH} 2.5$ with phosphoric acid and distilling under vacuum without heating. A titration curve was then plotted, the $\mathrm{pH}$ being measured after successive additions of $0.1 \mathrm{ml}$. portions of $0.01 \mathrm{~N}$-sodium hydroxide to the distillate, and compared with curves obtained with solutions containing known amounts of acetic acid in the same volume. Recoveries of acetic acid added to untreated ovomucoid were satisfactory. It was estimated that about $0.21 \mathrm{mg}$. of acetic acid was formed from $320 \mathrm{mg}$. of ovomucoid, which corresponds to only about $\mathbf{0 . 3} \mathrm{mole} / \mathrm{mole}$ of the mucoprotein.

Another correction necessary is that for cleavage of peptide bonds. To estimate this, other proteins were put through the same procedure, but the choice of suitable ones was limited by the fact that many are precipitated during the treatment. With casein and with crystalline bovine chymotrypsinogen, apparent acid production was comparable with that with ovomucoid (Table 1). Dephosphorylation may contribute in the former case, but the even higher value obtained with the latter protein presumably reflects appreciable peptide cleavage. With resin-treated digest, however, in which the content of peptide bonds is drastically reduced, acid production was again comparable with that from the amount of ovomucoid from which it derived (Table 1).

Attempts to detect split products. With submaxillary mucoprotein, Gottschalk \& Murphy (1961) showed that treatment with alkali releases disaccharide prosthetic groups. Attempts were therefore made to detect an analogous splitting of carbohydrate from ovomucoid, but no such effect could be conclusively demonstrated. When ovomucoid was treated with alkali under the above conditions, no appreciable proportion of the hexose or glucosamine became dialysable. Moreover, during paper electrophoresis (systems $\mathrm{E}$ and $\mathrm{F}$ ), protein and carbohydrate still moved together and at the same rate as untreated ovomucoid. When protease fragment was similarly treated with alkali, slight peptide hydrolysis occurred, since traces of the constituent amino acids could be detected in system $\mathrm{E}$, but the main band moved with the same mobility as untreated protease fragment and proved, on elution and hydrolysis, to have the same composition.

\section{Reducing power}

Reducing power was estimated by the method of Somogyi (1952), with the arsenomolybdate chromogen of Nelson (1944). With ovomucoid a slight 
precipitate was formed, which was centrifuged off before measurement of the blue colour but which may have impaired the accuracy of the results to some extent. The reducing power/mole of ovomucoid was equivalent to that of approx. 3 moles of mannose. With resin-treated digest in comparable amounts, however, no reducing power was detected. The inference would seem to be that proteolysis decreases the reducing power of ovomucoid, and preliminary experiments (J. G. Beeley and F. R. Jevons, unpublished work) seem to indicate that this is so.

\section{DISCUSSION}

Since the protease fragment was the only hexosecontaining fraction obtained on paper electrophoresis, and since it showed a content of glucosamine, mannose and galactose resembling that of intact ovomucoid, it is believed to contain at least the major portion, if not the whole, of the carbohydrate moiety of the mucoprotein. The failure to separate protease fragment into more than one component suggests that this carbohydrate is present as a single large prosthetic group on the protein, although it is also possible that it is present as two or more smaller groups, all similar in composition. The amino acid portion of the protease fragment seems to be heterogeneous, since four different $N$-terminal residues were detected. Though this might indicate that carbohydrate is attached to different portions of peptide chain, it seems at least as likely that the amino acids in the protease fragment represent the remnants of a unique portion of the chain, degraded with varying degrees of completeness by the proteases. The action of these enzymes might well be impeded by steric hindrance due to the carbohydrate near its point of attachment to the peptide chain. In the systems used for attempts to fractionate the protease fragment, the rate of movement must be determined predominantly by the bulky carbohydrate portion, and it would not be surprising if molecules differing only by the presence or absence of two or three amino acid residues failed to separate.

\section{Sugar-amino acid link}

When ovomucoid in unbuffered solution at $\mathrm{pH} 10.4$ was heated at $80^{\circ}$, a decrease in $\mathrm{pH}$ similar to that attributed to splitting of glycosidic ester bonds in submaxillary mucoprotein (Gottschalk \& Murphy, 1961) was observed, but the similar falls observed in various controls make it difficult to draw any definite conclusions. Several types of reaction other than ester hydrolysis can be envisaged which might contribute to acid formation under such conditions, e.g. peptide hydrolysis, oxidative degradation of the carbohydrate and saccharinic acid formation. Even if glycosidic ester bonds are present, the failure to detect splitting by the action of dilute alkali does suggest that they are not the only type of link joining carbohydrate to peptide chain in ovomucoid and protease fragment.

Certain considerations based on the results reported here favour the idea of $O$-glycosidic bonds formed from the hydroxyl groups of serine or threonine or both:<smiles>[X]C(=O)C(NC)C([R])O[SnH3]</smiles>

Such a structure provides a possible explanation of the fact that ovomucoid shows stronger reducing properties than the protease fragment. The presence of a carbonyl or other electron-attracting group in the $\beta$-position is known to render $O$-glycosides alkali-labile and hence reducing towards alkaline copper reagents, and the degree of lability varies with the electron-attracting power of the carbonyl group, decreasing in the series: ketone, ester, anilide (Ballou \& Link, 1950; Ballou, 1954). A serine or threonine residue in a peptide chain ( $\mathrm{X}=\mathrm{NHR}^{\prime}$ ) would have such a carbonyl group suitably placed in relation to a glycosidic bond formed from the hydroxyl group of the same residue. This is the situation imagined to exist in intact ovomucoid, and to be responsible for its reducing properties. If, during proteolysis, the peptide bond involving this carbonyl group is split, a carboxylate group results $\left(\mathrm{X}=\mathrm{O}^{-}\right)$, which would be expected to exert a smaller labilizing effect on the glycosidic link. This is the situation imagined to exist in the protease fragment. Analogies for such a change in stability on liberation of a carboxyl group are known. Thus pectin and methyl alginate are more labile to alkali than their de-esterified counterparts (Whistler \& Bemiller, 1958). The dephosphorylation of casein by alkali, which is believed to proceed by a similar mechanism, takes place more readily than the hydrolysis of serine $O$-phosphate (Anderson \& Kelley, 1959).

Some support for the above view comes from the results of analysis of the protease fragment for $N$-terminal residues, which yielded DNP derivatives of all the amino acids present except serine and threonine. This suggests that these two amino acids are at or near the $C$-terminal ends of the peptide chain or chains. Carboxypeptidase has been observed in other cases to liberate serine and threonine from proteins (Harris, $\mathrm{Li}$, Condliffe \& Pon, 1954; Harris \& Knight, 1955). Its failure to act on the protease fragment may perhaps be attributed to the proximity of a large carbohydrate group. 
Since the type of link here postulated in ovomucoid is markedly sensitive to alkali, and since the liberation of carbohydrate from ovomucoid under the influence of dilute alkali has not been observed, it remains possible that another type of link is also present. Structures involving aspartic acid, such as have been suggested for egg albumin (Cunningham et al. 1957; Jevons, 1958; Johansen et al. 1958, 1961) and human $\gamma$-globulin (Rosevear \& Smith, 1958, 1961), are not excluded for ovomucoid, since this amino acid is present in the protease fragment.

\section{SUMMARY}

1. Purified hen ovomucoid was extensively degraded by proteolytic enzymes, and the resulting carbohydrate-rich fragment (the 'protease fragment') was isolated from the digest by ionexchange and paper electrophoresis.

2. The protease fragment contained hexose, glucosamine, aspartic acid, threonine, serine, alanine, glycine and leucine in the approximate molar ratios 5:8:1:1:1:1:1:0.5. The hexose comprised mannose and galactose in a ratio similar to that in intact ovomucoid.

3. The protease fragment appeared to be homogeneous by paper chromatography and paper electrophoresis. $N$-Terminal residues of aspartic acid, alanine, glycine and leucine were detected. Carboxypeptidease had no observable action on it. Its isoelectric point was in the $\mathrm{pH}$ region 5-6.

4. Heat-treatment of ovomucoid in unbuffered solution at $\mathrm{pH} 10.4$ caused a fall in $\mathrm{pH}$, but the significance of this is not clear. Such alkali treatment apparently did not split carbohydrate from protein or peptide in ovomucoid or protease fragment.

5. Ovomucoid shows greater reducing power towards an alkaline copper reagent than a corresponding amount of protease fragment.

6. The nature of the link or links between sugar and amino acid residues in ovomucoid is discussed, and considerations are brought forward that suggest $O$-glycosidic bonds with the hydroxyl groups of serine or threonine or both.

One of us (F.K.H.) is indebted to the Department of Scientific and Industrial Research for a Studentship.

\section{REFERENCES}

Aminoff, D., Morgan, W. T. J. \& Watkins, W. M. (1952). Biochem. J. 51, 379.

Anderson, L. \& Kelley, J. J. (1959). J. Amer. chem. Soc. 81, 2275.
Ballou, C. E. (1954). Advanc. Carbohydr. Chem. 9, 59.

Ballou, C. E. \& Link, K. P. (1950). J. Amer. chem. Soc. 72, 3147.

Bettelheim-Jevons, F. R. (1958). Advanc. Prot. Chem. 13, 35.

Blackburn, S. \& Lowther, A. G. (1951). Biochem. J. 48, 126.

Bragg, P. D. \& Hough, L. (1961). Biochem. J. 78, 11.

Cunningham, L. W., Nuenke, B. J. \& Nuenke, R. B. (1957). Biochim. biophys. Acta, 26, 660.

Fraenkel-Conrat, H. \& Porter, R. R. (1952). Biochim. biophys. Acta, 9, 557.

Fredericq, E. \& Deutsch, H. F. (1949). J. biol. Chem. 181, 499.

Gottschalk, A. \& Ada, G. L. (1956). Biochem. J. 62, 681.

Gottschalk, A. \& Murphy, W. H. (1961). Biochim. biophys. Acta, 46, 81 .

Harris, J. I. \& Knight, C. A. (1955). J. biol. Chem. 214, 215.

Harris, J. I., Li, C. H., Condliffe, P. G. \& Pon, N. G. (1954). J. biol. Chem. 209, 133.

Hartley, F. K. \& Jevons, F. R. (1962). Biochem. J. 82, 1 P.

Jevons, F. R. (1958). Nature, Lond., 181, 1346.

Jevons, F. R. (1960). Biochim. biophys. Acta, 45, 384.

Johansen, P. G., Marshall, R. D. \& Neuberger, A. (1958). Nature, Lond., 181, 1345.

Johansen, P. G., Marshall, R. D. \& Neuberger, A. (1961). Biochem. J. 78, 518.

Lewis, J. C., Snell, N. S., Hirshman, D. J. \& FraenkelConrat, H. (1950). J. biol. Chem. 186, 23.

Lineweaver, H. \& Murray, C. W. (1947). J. biol. Chem. 171, 565.

Marshall, R. D. \& Neuberger, A. (1960). Nature, Lond., 186, 311.

Muir, H. (1958). Biochem. J. 69, 195.

Nelson, N. (1944). J. biol. Chem. 153, 375.

Nicol, D. S. H. W. (1960). Biochem. J. 75, 395.

Pénasse, L., Jutisz, M., Fromageot, C. \& Fraenkel-Conrat, H. (1952). Biochim. biophys. Acta, 9, 551.

Rosevear, J. W. \& Smith, E. L. (1958). J. Amer. chem. Soc. $80,250$.

Rosevear, J. W. \& Smith, E. L. (1961). J. biol. Chem. 236, 425.

Sanger, F. \& Thompson, E. O. P. (1953). Biochem. J. 53, 366.

Schwert, G. W. \& Takenaka, Y. (1955). Biochim. biophys. Acta, 16, 570.

Somogyi, M. (1952). J. biol. Chem. 195, 19.

Stacey, M. \& Woolley, J. M. (1940). J. chem. Soc. p. 184.

Stacey, M. \& Woolley, J. M. (1942). J. chem. Soc. p. 550.

Tillmans, J. \& Philippi, K. (1929). Biochem. Z. 215, 36.

Toennies, G. \& Homiller, R. P. (1942). J. Amer. chem. Soc. 64, 3045.

Turner, R. A. \& Schmerzler, G. (1954). Biochim. biophys. Acta, 13, 553.

Whistler, R. L. \& Bemiller, J. N. (1958). Advanc. Carbohyd. Chem. 13, 289.

Wilson, C. M. (1959). Analyt. Chem. 31, 1199. 